\title{
CAPITAL IMOBILIÁRIO E DESENVOLVIMENTO URBANO
}

\author{
Inaiá Maria Moreira de Carvalho*
}

\begin{abstract}
Este artigo analisa como a difusão do padrão de governança centrado na busca de uma "competitividade urbana" tem levado o Estado a abandonar parte de suas funções tradicionais de gestão e planejamento urbano, transferindo-as para atores privados, o que constitui uma afirmação crescente da lógica do capital imobiliário sobre a estrutura das cidades e a vida de suas populações. Discutindo a evolução recente de três capitais brasileiras, Natal, São Paulo e Salvador, ele analisa os discursos e procedimentos que vêm sendo utilizados para justificar e legitimar esse novo padrão de governança, assim como destaca seus efeitos adversos em termos sociais, ambientais e urbanos.

PALAVRAS-CHAVE: Metrópoles. Capital imobiliário. Desenvolvimento urbano.
\end{abstract}

\section{INTRODUÇÃO}

Este trabalho se propõe a discutir como o capital imobiliário vem assumindo atualmente um novo protagonismo no desenvolvimento das grandes cidades brasileiras, a partir da análise da trajetória recente das cidades de Natal, São Paulo e Salvador. Ele se insere no debate sobre a nova ordem social e espacial que estaria sendo produzida pelas transformações contemporâneas do capitalismo nos grandes centros urbanos, debate que, no plano internacional, foi iniciado com as reflexões de autores como Sassen (1991), Veltz (1996), Borja e Castels (1997) ou Marcuse e Kempen (2000), e que tem se desdobrado em numerosas pesquisas

\footnotetext{
* Doutora em Sociologia. Professora do Programa de PósGraduação em Ciências Sociais da Universidade Federal da Bahia (UFBA) e do Mestrado em Políticas Sociais e Cidadania da Universidade Católica do Salvador, Brasil. Pesquisadora do Centro de Estudos e Pesquisas em Humanidades - CRH - da Universidade Federal da Bahia, do CNPq e do Observatório das Metrópoles - Brasil.

Avenida Anita Garibaldi, 2981. Rio Vermelho. Cep: 41940210. Salvador - Bahia - Brasil. inaiammc@ufba.br A autora agradece a Marlise Duarte, Maria do Livramento Clementino, Lúcia Bógus, Suzana Pasternack e João Marcos pelas contribuições e comentários à análise dos casos de Natal e de São Paulo.
}

sobre as metrópoles do Brasil e da América Latina.

Tais pesquisas têm evidenciado que, embora quase todas essas cidades sejam, de alguma forma, afetadas pelas mencionadas transformações, seu envolvimento nelas depende da natureza e do alcance desse processo (que não é uniforme nem converge para um modelo único de cidade), e sua dinâmica é definida pela continuidade e pela mudança, já que o preexistente condiciona a emergência do novo, o qual, em muitos casos, já começara a se esboçar no passado (Mattos, 2004). Notadamente, isso vale para as estruturas urbanas, que, como ressalta Préteceille (2003), não podem ser interpretadas como um efeito direto das transformações recentes, pois constituem uma herança histórica dos efeitos de economia e da sociedade no longo prazo, o que se evidencia tanto nas estruturas materiais do espaço construído como nas formas sociais de valorização simbólica e de apropriação.

Por isso mesmo, estudos efetuados sobre as grandes metrópoles do Brasil, do Chile, do México, do Uruguai e da Argentina têm constatado uma relativa estabilidade de suas estruturas social e 
urbana. ${ }^{1}$ Contudo, essa estabilidade não impede que se verifiquem algumas transformações comuns, com modalidades e alcance específicos em cada cidade. Destacam-se, entre elas, mudanças na estrutura econômica e social dessas cidades. Tais mudanças são associadas à reestruturação produtiva e a outras exigências da nova fase de desenvolvimento capitalista, como uma relativa desindustrialização, um avanço e uma maior diversificação das atividades terciárias, flexibilização das relações de trabalho e um aumento das desigualdades. Caracterizam-se pela expansão desses centros para as bordas e para o periurbano, assim como o descenso demográfico, o empobrecimento ou a própria deterioração de antigas áreas centrais, paralelamente ao surgimento de novas centralidades, muitas vezes associado à edificação de equipamentos de grande impacto na estruturação do espaço urbano, como shopping centers, grandes hospitais, complexos empresariais ou centros de convenções. Há ainda a difusão de novos padrões habitacionais, com inversões imobiliárias destinadas aos grupos de alta e média renda e a proliferação de condomínios verticais e horizontais fechados e protegidos por dispositivos explícitos de separação física e simbólica, como cercas, muros e sofisticados aparatos de segurança, o que amplia progressivamente a autossegregação dos mais ricos, a fragmentação e as desigualdades urbanas. Finalmente, há o abandono, por parte do Estado, de boa parte das suas funções tradicionais de planejamento e gestão urbana e metropolitana, que vêm sendo transferidas para atores privados e levam a uma afirmação crescente da lógica do capital imobiliário na produção e reprodução dessas cidades, com impactos decisivos sobre a estrutura urbana e a vida de sua população.

No que se refere a essa última transformação, objeto do presente trabalho, inicialmente é preciso reconhecer que, nas sociedades capitalistas, a interferência do capital imobiliário sobre o desenvolvimento urbano não constitui uma novi-

${ }^{1}$ Ver, por exemplo, Taschner; Bógus, 1999; Ribeiro, 2004; Mattos, 2004 e 2010 a e b; Shapira, 2000; Janoschka, 2002; Duhau, 2005; Sabatini, Cáceres, Cerda, 2004 Bayon, 2008; Carvalho, Pereira 2008 e 2010, Cordera; Kuri; Zicardi, 2008; Gonzalez, 2010, Veiga, 2010. dade. Como bem ressaltam Logan e Molotch (1987), nessas sociedades, a produção do espaço urbano envolve um conflito entre o seu valor de uso e o seu valor de troca, o que opõe, de um lado, os moradores da cidade, interessados, sobretudo, na defesa da sua qualidade de vida, e, de outro, uma coalizão de interesses econômicos, comandada pelo capital imobiliário, que busca um maior retorno financeiro e uma ampliação dos seus lucros, com a transformação da cidade em uma espécie de "máquina de crescimento”.

Ao longo do processo de urbanização do Brasil, como se sabe, os interesses dessa coalizão foram sempre dominantes. Embora o modelo das grandes cidades europeias estivesse no imaginário de suas elites, nas condições do desenvolvimento do país (marcado pelo seu caráter excludente e pela sua incapacidade de integrar plenamente as massas urbanas), as orientações que presidiram a expansão das cidades e o modelo de planejamento urbano modernista e funcionalista não chegaram a se generalizar. Definindo os padrões de ocupação e uso do solo e apoiado na centralidade e racionalidade do aparato do Estado, esse modelo estendeu-se apenas a uma parte das cidades, a denominada cidade "legal” ou "formal". Embora a maioria delas dispusesse de um Plano Diretor e de órgãos encarregados de sua aplicação, esses planos ignoravam a cidade "informal" e suas áreas de pobreza, desequipadas e desassistidas, bem como questões como circulação, segregação e distribuição dos serviços e equipamentos. O crescimento urbano ocorreu à margem desses planos, que, como assinalam Villaça (2005) e Maricato (2002), transformaram-se em "planos-discurso", com um conteúdo genérico e restrita ou nenhuma aplicação, cumprindo um papel eminentemente ideológico e ajudando a encobrir o motor que efetivamente comanda os investimentos e a expansão urbana: os grupos dominantes locais, o capital imobiliário e as empreiteiras.

É verdade que, na fase de redemocratização do Brasil, foi criado e ganhou força um amplo movimento social com a bandeira da reforma urbana, reunindo movimentos populares por mora- 
dia, transporte e saneamento, associações profissionais ligadas à questão urbana, entidades acadêmicas e sindicais, grupos católicos ligados à Teologia da Libertação e prefeitos de partidos de esquerda. A atuação desse movimento levou à incorporação, na Constituição de 1988, de determinados dispositivos e à posterior aprovação do Estatuto das Cidades, que se orientava para a preservação da função social e ambiental e para a gestão democrática desses centros, incluindo instrumentos, mecanismos, processos e recursos para a sua realização. Contudo, apesar de um reconhecimento internacional, as disposições do Estatuto têm sido muito pouco observadas, persistindo ignoradas, contestadas ou objeto de uma intensa disputa sociopolítica e jurídica.

Nessas circunstâncias, com as transformações econômicas e sociais contemporâneas, o caráter, a dimensão e os impactos do conflito de interesses em torno do processo de desenvolvimento urbano também se modificaram e se ampliaram, conforme autores como Duhau (2005) e Mattos (2010a; 2010b) e a própria observação empírica deixam patente. A difusão das tecnologias de comunicação e informação, a ampliação da malha viária e o uso crescente do automóvel têm viabilizado novas formas de mobilidade e conectividade e reduzido o peso do fator distância, provocando mudanças no comportamento locacional de famílias e empresas, com a escolha de lugares mais distantes do centro urbano e uma ampliação e reconfiguração do território urbano e metropolitano. Tais mudanças associam-se à exigência de novos espaços e de infraestrutura para abrigar as novas atividades hegemônicas (como serviços financeiros, consultoria, informática ou assessoria), o turismo e a moradia, bem como o consumo e o lazer das camadas de alta e média renda, o que tem demandado a ampliação e a reconfiguração da malha urbana e estimulado a construção civil.

A isso se soma a aceleração dos fluxos de capital produzidos pela globalização financeira sob o estímulo das políticas de liberalização econômica (parte não desprezível orientada para a inversão imobiliária, assim como recursos do crime organizado e do narcotráfico) e um novo enfoque de governança, que se rege pelos princípios de subsidiariedade estatal, ênfase nos mecanismos de mercado e busca de competitividade urbana, deixando em plano absolutamente secundário o acesso mais justo aos fundos públicos, a redistribuição de renda e a proteção ambiental.

Sob a influência do ideário neoliberal, de agências multilaterais e de alguns consultores internacionais, em muitas cidades da América Latina, a governança vem assumindo um novo significado, com o abandono da matriz de planejamento racionalista e funcionalista e a adoção do denominado "empreendedorismo urbano". Discutida por autores como Harvey (2005), Vainer (2002), Maricato (2002), Gonzalez (2010) e Mattos (2010a; 2010b), essa governança se inspira em conceitos e técnicas oriundas do planejamento empresarial, compreende a cidade, principalmente, como sujeito ou ator econômico e vê como eixo central da questão urbana a busca de uma competitividade orientada para atrair os capitais que circulam no espaço sem fronteiras do mundo globalizado, de forma a ampliar os investimentos e as fontes geradores de empregos.

Para o alcance desse objetivo, competiria aos governantes locais utilizarem estratégias de marketing para a promoção e "venda" da imagem de sua cidade, considerando as expectativas e demandas do mercado nas suas decisões e ações e criando um ambiente favorável e atrativo para os investimentos. Mirando-se principalmente na experiência de Barcelona, $^{2}$ entre outros aspectos, isso envolve uma mercantilização e uma espetacularização da cidade, com a edificação de grandes equipamentos culturais, a gentrificação de certas áreas, a atração de

${ }^{2}$ Idealizando experiências como as de Baltimore, Frankfurt e Barcelona, os entusiastas do planejamento estratégico não levam em conta que, nessas cidades, as principais demandas coletivas já se encontravam atendidas, sua população desfrutava de um padrão de vida satisfatório e as novas orientações foram articulados a um planejamento mais abrangente, o que não ocorre nos grandes centros do Brasil e da América Latina. Além disso, como este trabalho deixa evidente, as formulações sobre as "cidades globais" e sobre o empreendedorismo urbano também vêm sendo utilizados para tentar encobrir e justificar casos patentes e até comprovados de corrupção. 
grandes eventos internacionais, o estabelecimento de parcerias público-privadas e uma maior flexibilidade e liberdade para a operação do capital. Como bem ressalta Mattos (2010a; 2010b), essas orientações favorecem especialmente os investimentos imobiliários, com os quais os governantes locais vêm tendendo a negociar as condições para a sua maior expansão, incluindo, entre elas, a flexibilização das normas relativas ao parcelamento e uso do solo e os códigos de edificação antes estabelecidos para orientar e controlar o desenvolvimento urbano.

Com a restrição dos recursos, das inversões e das ações estatais, a ênfase nos mecanismos de mercado e a nova primazia do capital imobiliário, esse desenvolvimento se consolida agora dentro de uma lógica mais estritamente capitalista, ignorando, deixando em segundo plano ou até contrariando as necessidades e demandas mais amplas da maioria da população.

Como assinalam Carvalho e Pereira (2011), no caso do Brasil, também é preciso levar em conta que o crescimento econômico dos últimos anos tem se refletido especialmente nas funções da cidade e no estímulo à construção civil. As demandas por infraestrutura e novos espaços para atividades produtivas, habitação, turismo, consumo e lazer (especialmente para as camadas de média e alta renda), assim como a dimensão da demanda habitacional reprimida, as políticas nacionais de incentivo à habitação de interesse social, a ampliação do crédito, do emprego e da renda, tornaram o mercado imobiliário brasileiro um dos mais dinâmicos do mundo. Só o mercado de Hong Kong vem apresentando um melhor desempenho. Somado à recente crise financeira e imobiliária dos países centrais, isso vem tornando o mercado nacional bastante atrativo para os capitais internacionais (The Economist, 2011; Exame, 2011).

Nesse contexto, o capital imobiliário e a coalisão de interesses por ele comandada vêm adquirindo novo poder e protagonismo no que tange ao desenvolvimento das cidades, acentuados, inclusive, pelo seu atual porte e perfil, pela sua maior capacidade de intervenção no espaço urbano e pelo grau de liberdade que passaram a desfrutar a partir das orientações e do discurso do "empreendedorismo urbano".

As principais empresas atuantes nesse mercado não têm mais um caráter local ou regional. ${ }^{3}$ Trata-se, agora, de grandes conglomerados, muitas vezes internacionalizados, que constroem obras como barragens, pontes e metrôs, e que, tendo participado dos processos de privatização, atuam, hoje, em ramos como a petroquímica, telecomunicações ou a limpeza pública das grandes cidades. Exemplos dessas empresas são a Odebrecht e a OAS, que, na sua origem, eram empreiteiras baianas e hoje podem ser caracterizadas como multinacionais presentes em diversos setores da economia, ou a Cyrela, que, em dezembro de 2010, possuía 205 obras em andamento no país, e uma previsão de vendas de oito bilhões de reais para 2011. E, como o tamanho dos empreendimentos é proporcional ao dos players, essas empresas possuem agora um novo poder de interferência sobre a estrutura urbana, conforme será visto nas páginas que se seguem.

\section{O NOVO PROTAGONISMO DO CAPITAL IMOBILIÁRIO}

\section{A trajetória de Natal}

O novo protagonismo do capital imobiliário foi analisado a partir de um conjunto de documentos e entrevistas com informantes qualificados (membros da academia e do Ministério Público, urbanistas e participantes de movimentos sociais) sobre a trajetória recente de três capitais que expressam a diversidade das características socioeconômicas, demográficas e urbanas das cidades brasileiras, Natal, São Paulo e Salvador, onde a relevância do fenômeno em apreço vem se mostrando evidente.

A primeira dessas cidades é a capital do Rio Grande do Norte, um estado com uma participação pouco significativa na vida econômica do

Sobre o perfil das empresas e o processo recente de
reestruturação do setor imobiliário no Brasil, ver Cardoso e Aragão, 2012. 
país, mas que, a partir da década de 1970, experimentou um significativo crescimento econômico, com a implantação, em seu território, de novas e modernas atividades, a exemplo de um polo têxtil e de confecções, da carcinicultura e de um polo de fruticultura irrigada para exportação, da exploração de petróleo na Bacia Potiguar e de uma grande expansão do turismo no seu litoral.

Contando com apenas 359.936 habitantes em 1980, Natal foi beneficiada pelos impactos diretos e indiretos dessas novas atividades e, especialmente, pela implantação de uma ampla infraestrutura turística para a exploração de suas características culturais e ambientais. A estrutura econômica e urbana da cidade se transformou, experimentando uma significativa expansão e modernização. Sua população cresceu bastante, chegando a 712.312 habitantes no ano 2000 e a 803.739 em 2010, além de comandar uma região metropolitana com 1.351.004 moradores segundo o último Censo (Clementino, 2003).

Como seria de esperar, o processo de expansão e modernização da cidade foi estreitamente articulado com a expansão imobiliária, elevando o preço de terra urbana e dos imóveis e estimulando a especulação, entre outros aspectos, porque os encantos naturais dessa capital começaram a atrair europeus em busca de uma segunda residência nos trópicos, com baixos custos, tendo em vista o poder aquisitivo de suas moedas no mercado imobiliário local.

Embora a cidade não escapasse dos "planosdiscurso", a preservação do meio ambiente e do cenário paisagístico é uma antiga preocupação local e, por isso, já em 1984, o seu Plano Diretor procurou proteger algumas áreas consideradas como patrimônio da sociedade e como áreas especiais turísticas, como o Parque das Dunas, a enseada de Ponta Negra e o Morro do Careca. Além disso, conforme o rico estudo de Duarte (2011), em 1994, Natal passou a contar com um Plano Diretor que representou um marco na construção de direitos e na definição de espaços protegidos na cidade.

Com uma origem política e intelectual vinculada ao movimento de reforma urbana, esse pla- no foi elaborado a partir de um extenso e aprofundado diagnóstico da cidade real e com uma ampla participação de intelectuais, urbanistas, entidades profissionais, movimentos ecológicos e movimentos populares locais. Orientando-se para o pleno desenvolvimento das funções sociais da propriedade urbana e da cidade e procurando assegurar o uso socialmente justo e ecologicamente equilibrado do seu território, ele incorporou vários princípios e mecanismos inovadores (que vieram, posteriormente, a ser incluídos no Estatuto das Cidades), como a outorga onerosa, a transferência do potencial construtivo, o IPTU progressivo no tempo, a criação de zonas especiais de interesse social e ambiental (com destino específico e normas próprias de uso e ocupação do solo) e de um fundo de habitação para investimentos de interesse social.

Mas nem todas essas disposições se materializaram. ${ }^{4}$ Com a mudança do prefeito e da composição da Câmara, cresceram as pressões para uma revisão do Plano, orientadas pelos interesses do setor imobiliário. Com o pretexto de que sua rigidez estaria prejudicando a cidade em termos da implantação de uma infraestrutura urbana moderna e do recolhimento de impostos, a nova administração municipal assumiu outra postura, passando a promover modificações fragmentadas para viabilizar (sem grandes questionamentos e reações) um maior adensamento das áreas mais valorizadas e cobiçadas da cidade, cujo crescimento e modernização continuavam a ser impulsionadas principalmente pelo turismo. Isso desencadeou processos de caráter segregador e elitista, com a verticalização de certas áreas, a expansão de condomínios horizontais fechados, a implantação de grandes equipamentos de comércio e serviços para as camadas de maior renda e a ocupação de áreas distantes e frágeis pelos grupos mais pobres.

Em 2004, iniciaram-se os trabalhos relativos à revisão do Plano Diretor de 1994, que termi-

${ }^{4}$ Como assinala Duarte, no que tange à regularização e urbanização das ocupações populares, por exemplo, as intervenções foram pontuais e limitadas, e nem todas as áreas de proteção ambiental foram realmente institucionalizadas. 
nou sendo aprovado em 2007, mas com uma tramitação bastante tumultuada. Essa revisão contou com uma intensa participação dos diversos segmentos da sociedade e discutiu amplamente as condições, os problemas e os destinos da cidade. Contudo, quando o texto com o projeto de lei foi levado para a apreciação da Câmara, os vereadores introduziram um conjunto de emendas de interesse do capital imobiliário, suprimindo a proteção à paisagem da Via Costeira e a possibilidade de o poder executivo institucionalizar novas áreas non edificandi, reduzindo o percentual da outorga onerosa e prorrogando o prazo para o seu pagamento, elevando o potencial construtivo de diversas áreas e o gabarito de outras especialmente cobiçadas pelos construtores, como o entorno do Parque das Dunas e o bairro de Mãe Luiza. ${ }^{5}$

Essas emendas foram aprovadas em uma sessão fechada, à qual tiveram acesso poucas pessoas escolhidas e com senhas distribuídas pelos vereadores, suscitando uma grande indignação da sociedade, principalmente quando se descobriu que essa aprovação fora viciada pela corrupção dos 16 vereadores que a apoiaram. Essa corrupção foi comprovada (e cinco anos depois os vereadores condenados), o Ministério Público entrou com uma ação direta de inconstitucionalidade e as referidas emendas terminaram não surtindo efeitos, com a afirmação, no novo Plano, dos princípios, deterresse ambiental e turístico, passaria a ser permitida a construção de edifícios com até 31 andares. O bairro de Mãe Luiza, protegido como zona especial de interesse social, seria afetado por uma emenda aparentemente inofensiva sobre terrenos lindeiros, cuja aprovação elevaria o seu potencial construtivo, estimulando a compra dos seus modestos imóveis pelas construtoras e a expulsão branca de sua população.
Grande do Norte, um Plano de Desenvolvimento do Setor Imobiliário e da Construção Civil, oferecendo-lhe uma série de benefícios em termos tributários, ambientais e sociais, além de assinalar a necessidade de "[...] reconciliar a prefeitura de Natal com a totalidade dos mercados imobiliários e da construção civil”' (Duarte, 2011, p.463).

Empenhou-se na divulgação dos atributos positivos e na "venda" da cidade, apresentando-a como um lugar ideal e seguro para investir e para viver, em declarações como a que foi publicada em um caderno de propaganda da Real Estate Investiments de Propriedades Imobiliárias, onde a prefeita enfatiza que: Los embestidores serán tratados como socios -
en una sociedad que debe ser reflejada en
beneficios para las personas que viven en Natal
tras la generación de empleos mejores, rentas y
calidad de vida. En eso contexto el segmento
inmobiliario es considerado como un dos más
importantes pela la economía de la ciudad de
Natal. El gobierno municipal reconoce ese valor
y valonara nuevas inversiones, garantiendo la
seguridad jurídica a los proyectos que están den-
tro de las reglas y leyes establecidas (Duarte,
2011, p. 468).

Entre outras iniciativas, a referida "reconciliação" envolveu a realização de um grande mutirão para agilizar a concessão de novas licenças construtivas (em uma semana, 200 delas foram liberadas); o envio de um projeto de lei à Câmara Municipal propondo a alteração de várias prescrições do Plano de 2007 e recuperando o que ficou conhecido como a "emenda do Mãe Luiza; além da revisão e a liberação de grandes empreendimentos em zonas especiais de interesse ambiental, contrariando frontalmente os dispositivos legais que asseguram sua proteção. Não por acaso um dos representantes do setor imobiliário chegou a explicitar que "[...] a prefeitura teve uma visão agora muito mais focada no mercado do que simplesmente se prendendo à legislação. Ou seja, adequou a legislação ao mercado. Foi um passo importante, porque o mercado é muito dinâmico" (2011, p. 46).

É verdade que a pronta reação do Ministério Público e a significativa mobilização da sociedade organizada barraram algumas das referidas 
iniciativas e levaram a prefeitura a retirar sua proposta de modificação do Plano Diretor vigente, cujo conteúdo não sofreu alterações substanciais. Contudo, na avaliação de Duarte, os embates em torno desse conteúdo e a estreita aliança entre o executivo municipal e os interesses imobiliários contribuíram para fragilizar os direitos e avanços conquistados desde o Plano Diretor de 1994. Isso se evidenciaria, por exemplo, pela não regulamentação de alguns espaços especiais de interesse social e ambiental, do processo de outorga onerosa e dos instrumentos voltados para evitar a retenção especulativa de imóveis, pela persistente ameaça a zonas especiais de interesse social (como o bairro de Mãe Luiza), ou pela liberação de licenças para a edificação de grandes empreendimentos em áreas de fragilidade ambiental, com riscos de efeitos adversos em termos da paisagem, da circulação dos ventos, do clima e da contaminação do solo. ${ }^{6}$

\section{A experiência de São Paulo}

Processos semelhantes vêm ocorrendo também em São Paulo, a maior e mais importante das capitais brasileiras, com uma população de 11.253.503 habitantes, que, juntamente com sua região metropolitana, concentra boa parte da produção industrial do país, sedes de grandes empresas, bancos, financeiras e serviços mais modernos e qualificados, articulando a economia nacional com os circuitos da economia mundializada e sendo qualificada por alguns como uma "cidade global" ou como candidata a sê-lo. Tanto essas características como as transformações e o crescimento recentes da economia brasileira têm ocasionado uma maior expansão da cidade e de sua região, estimulando bastante o crescimento das atividades imobiliárias e contribuindo para a emergência de novas formas de produção e consumo do espaço urbano, com a

\footnotetext{
${ }^{6}$ Em uma dessas áreas, o empreendimento residencial River Side ocuparia $39.191,50 \mathrm{~m}^{2}$, com sete torres de 15 pavimentos e uma previsão de 1470 moradores. Um outro, a Nova Petrópolis, envolveria a construção de 14 torres de 19 a 21 pavimentos em uma área de 89.099,83 $\mathrm{m}^{2}$, onde poderiam residir 3.808 pessoas (Duarte, 2011, p. 500).
}

multiplicação de grandes condomínios residenciais e multifuncionais, torres de escritório, casas de espetáculo, hotéis e centros de convenções.

Ocorre que alto crescimento demográfico e urbano dos grandes centros tem ocasionado uma escassez relativa do solo urbano e uma elevação do seu preço, levando os setores imobiliários a operarem crescentemente através da reconstrução e modernização de certas áreas da cidade e a buscarem uma maior rentabilidade para seus investimentos pela intensificação do uso do solo e pela edificação de novos e mais lucrativos tipos de empreendimentos (Cobos, 2012). Com isso, aumentaram as pressões e disputas por um maior acesso ao referido solo e pela ampliação de seus coeficientes de ocupação, notadamente em áreas mais valorizadas ou com potencial para elevar a sua valorização.

No caso de São Paulo, a intensificação em apreço vem sendo viabilizada principalmente através de parcerias entre o setor público e o privado para a reurbanização de determinados espaços da cidade, com um aumento substancial de seu potencial construtivo. Discutidas por autores como Fix (2001), Ferreira (2007), Pessoa e Bógus (2008) ou Nobre (2009), essas parcerias começaram a ser implementadas na segunda metade da década de 1980. Apresentadas, na época, como alternativas para resolver o problema das favelas na capital paulistana, de fato, elas justificaram alterações pontuais e casuísticas na lei do zoneamento e no Código de Obras de interesse do mercado imobiliário, mas tiveram um alcance restrito, pois não foram capazes de criar novas zonas de investimento maciço pelos diversos agentes privados, o que passou a ocorrer a partir de 1995, na gestão Maluf, com as chamadas Operações Urbanas Consorciadas. ${ }^{7}$

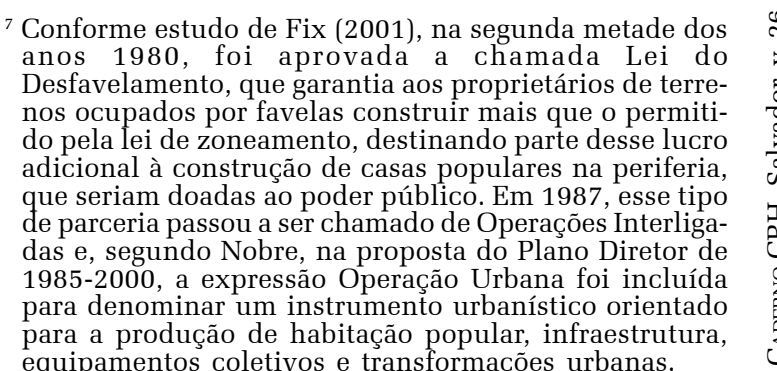


Constituindo um instrumento legal de renovação e (ou) de ampliação da infraestrutura urbana, essas operações são definidas como um conjunto de intervenções e medidas coordenadas pelo poder público municipal, com a participação da iniciativa privada, visando a alcançar transformações estruturais, melhorias sociais e a valorização ambiental de uma determinada área da cidade, com mudanças nos seus padrões de ocupação. Levando o município a atuar como indutor e regulador dessas transformações, viabilizando melhorias urbanas e a apropriação pública de parte dos ganhos gerados pelos investimentos privados mediante a cobrança do potencial adicional de construção, em tese, essas operações teriam um caráter progressista, redistributivo e coerente com as disposições do Estatuto da Cidade. Na prática, porém, não é isso que vem se dando, conforme pesquisas dos autores acima mencionados.

A implementação dessas operações não tem ocorrido a partir de um planejamento que leve em conta as necessidades e prioridades urbanísticas mais amplas da cidade, e sim como respostas a interesses específicos do mercado, restritos às áreas mais valorizadas e melhor equipadas do espaço urbano, no caso de São Paulo, ao quadrante sudoeste, onde se concentram a infraestrutura, os serviços e os bairros de maior renda. Para que a iniciativa privada venha efetivamente a participar dessas operações e arcar com parte de seus custos, também vem sendo preciso que o Estado amplie sua atratividade, com a realização de investimentos prévios e grandes obras públicas, concentrando recursos em áreas já privilegiadas, funcionando como um grande empreendedor imobiliário e, na expressão de Fix, como o principal "sócio" da iniciativa privada na renovação de grandes áreas da cidade, de forma a reduzir seus riscos e ampliar suas possibilidades de lucro. Ademais, melhorias sociais e ambientais e maiores ganhos para as finanças municipais não têm sido observados, registrando-se, antes, uma elitização das áreas afetadas pelas transformações em apreço (com a expulsão de parte de seus moradores), uma maior concentração da riqueza e um aumento das desi- gualdades sociais e urbanas, como deixa patente a mais conhecida dessas operações.

Trata-se da Operação Urbana Faria Lima, que começou a deslanchar em 1995, quando o então prefeito Paulo Maluf aprovou, na Câmara, uma proposta de extensão dessa avenida e de criação de uma centralidade terciária de alto nível na marginal do rio Pinheiros (região valorizada que ainda dispunha de terrenos relativamente extensos e baratos, com um valor fundiário bastante promissor), com a justificativa de que era necessário atender às novas demandas das grandes empresas globalizadas para ampliar a competitividade urbana de São Paulo e viabilizar sua vocação de cidade mundial.

Com esse discurso e a realização de grandes obras públicas, a área dessa operação se transformou na maior frente de negócios e de consumo, cercada por bairros residenciais de alto padrão, concentrando novas torres, "edifícios inteligentes" e outros megaempreendimentos e experimentando uma significativa valorização. Mas essas transformações também envolveram a erradicação de algumas favelas que ocupavam as margens do córrego de Águas Espraiadas (onde foi construída uma via expressa) e a substituição de antigas residências unifamiliares das classes médias por edifícios de alto padrão, com a expulsão ou deslocamento de pelo menos 20.000 dos antigos moradores ${ }^{8}$ e a elitização da área, com impactos sobre a conformação da cidade e sobre os seus padrões de segregação. Finalmente, a expectativa de que a operação seria autofinanciável não teve confirmação. Conforme avaliação de Ferreira (2007), em outubro de 2002, ela já teria custado aos cofres públicos mais de meio bilhão de reais e, de acordo com Nobre (2009), embora o município tenha arrecadado 306 milhões com a venda de quase um milhão de $\mathrm{m}^{2}$ adicionais, os gastos com as obras públicas chegaram a $715 \mathrm{mi}-$ lhões, beneficiando, fundamentalmente, proprietários de terrenos, construtoras e outras empresas e usuários do transporte individual.

\footnotetext{
${ }^{8}$ Conforme pesquisa de Fix (2001), sem outras alternativas de moradia, uma parte dos moradores das favelas terminou sendo transferida para as margens da empresa Billings, área de proteção de mananciais, em caminhões da própria prefeitura, que promoveu a ocupação e a transgressão da lei nas margens da referida empresa.
} 
Apresentam uma lógica similar as medidas recentemente tomadas para a requalificação da região da Luz, área degradada do Centro, que se tornou mais conhecida e vem sendo estigmatizada como a "Cracolândia”. Há anos que o poder público vem investindo nessa área, principalmente em equipamentos culturais, visando a modificar sua imagem negativa, atrair um novo público e desencadear um ciclo de investimentos privados pela valorização imobiliária de seu entorno. Em 2005, porém, essas iniciativas foram ampliadas e sofreram uma reorientação. Sem qualquer consulta ou discussão com os moradores, pequenos proprietários ou comerciantes locais, o então prefeito Gilberto Kassab lançou um projeto denominado Nova Luz, declarando de utilidade pública 362 hectares, com a previsão de $30 \%$ de demolição dos quarteirões ali incluídos. Também foi anunciado um programa de abatimentos e isenções fiscais para atrair possíveis investidores e desencadeadas ações para combater o consumo de crack e a concentração na área de seus consumidores.

Mas é a partir de 2009, segundo Mourad (2012), com a introdução da concessão urbanística e a aprovação da Operação Urbana Nova Luz, que vai se cristalizar uma articulação entre o poder local e o mercado, colocando a área em apreço no centro das atenções do capital imobiliário. Levando em conta não um projeto pré-elaborado, mas a experiência dos candidatos na recuperação de espaços degradados, a concessão urbanística transferiu para a iniciativa privada o poder de desapropriar imóveis residenciais e comerciais (cujo valor se encontra atualmente bastante depreciado) para reformar, demolir, construir e lucrar com sua valorização imobiliária e venda. Em troca, deveria ser implementado um processo de revitalização urbana que inclui a recuperação ou a edificação de (novas) calçadas, praças, creches, postos de saúde e ciclovias, assim como a implementação de um polo de comércio e de serviços e de uma área de cultura e entretenimento, com cinemas, teatros e cafés na região.

A proposta dessa revitalização não privilegia a produção de habitações de interesse social, orientando-se pela lógica seletiva e excludente do mercado, tampouco inclui mecanismos para restringir a expulsão dos atuais ocupantes da região. Além disso, os cofres públicos municipais deveriam repassar até $R$ \$355 milhões à empresa que vencesse a licitação para restaurar a área, uma vez que os cálculos de viabilidade econômica não consideraram o quanto o negociador dos futuros prédios iria lucrar com a venda dos imóveis e a transformação da área em um bairro moderno e com equipamentos públicos de primeira qualidade, apesar de o faturamento previsto chegar a $\mathrm{R} \$ 5,1$ bilhões em um período de 15 anos (Folha de S.Paulo, 12 ago. 2012).

Em agosto de 2011, o prefeito apresentou o projeto final de revitalização, anunciando que a empresa que faria a reforma seria escolhida no primeiro semestre de 2012 e que as obras começariam logo em seguida. Contudo, ameaçados pela gentrificação e pela expulsão, a Associação de Comerciantes do bairro de Santa Ifigênia ajuizou uma ação popular contra a Prefeitura do município de São Paulo, acolhida pela justiça com uma liminar que suspendeu a concessão urbanística em discussão. Apesar da insistência do poder local e do assédio de investidores nacionais e estrangeiros para a compra de imóveis, a população continuou mobilizada contra o projeto, e o enfrentamento persistiu, inclusive com a acolhida pelo judiciário de uma ação civil pública proposta pela Defensoria Pública de São Paulo, visando à sua anulação (Mourad, 2012). Com as eleições e a mudança recente da administração municipal, porém, o projeto foi paralisado, sendo anunciado que, embora a requalificação da área continue a ser prioritária, ela será revista, deixando de delegar poderes a expropriatórios da iniciativa privada, procurando dialogar como todos os interessados e investindo principalmente na produção de novas moradias populares. (Folha de S.Paulo, 16 dez 2012;1 e 16 fev. 2013).

A tentativa de venda de um terreno público no Itaim Bibi e a reação de moradores contra o avanço do capital imobiliário em diversos bairros paulistanos são igualmente ilustrativas do novo poder desse capital e de suas relações estreitas com o governo local. Em 2011, por sugestão do sindi- 
cato de empresas construtoras, o então prefeito Gilberto Kassab conseguiu aprovar na Câmara, na calada da noite, ${ }^{9}$ uma lei que o autorizava a negociar o chamado “quarteirão da cultura”, então em processo de tombamento, contra o parecer dos órgãos de preservação do patrimônio, o repúdio dos moradores do bairro e os protestos da sociedade mais ampla. Tratava-se de um valioso terreno municipal de $20.000 \mathrm{~m}^{2}$, localizado no Itaim Bibi (área nobre da cidade) e densamente arborizado, onde estão instalados serviços públicos que atendem a milhares de usuários e são reconhecidos pela sua excelência, como escolas, postos de saúde, teatro e biblioteca.

A entrega desse terreno, onde uma construtora pretendia edificar quatro prédios, cada um com 25 apartamentos de alto luxo, seria deita com a troca da construção de 200 creches na periferia, com o argumento de que a iniciativa privada teria mais agilidade que o poder público para localizar áreas, comprá-las e edificar essas creches. Mas a população reagiu (entre outras iniciativas, com um abaixo assinado com 12 mil assinaturas e um grande "abraço" ao quarteirão), descobriu-se que a venda de terrenos municipais só poderia servir para o pagamento de precatórios, e a transação foi barrada pela justiça, considerando que a referida lei poderia trazer prejuízos irreversíveis para a cidade (Folha de S.Paulo, 08 jul; 05 ago 2011). A área foi tombada (impedindo a construção de torres e deixando de interessar às construtoras), e a prefeitura terminou desistindo do plano, alegando não haver tempo hábil para implementá-lo nessa gestão.

Embora São Paulo seja uma cidade bastante verticalizada, com a construção de prédios elevados desde a década de 1920, ela também possui bairros tradicionais, onde predominam residências unifamiliares ao lado de um comércio local. Com o crescimento econômico, a escassez de terrenos e a ampliação do crédito imobiliário nos últimos anos, porém, vários desses bairros vêm sendo assediados e ameaçados de descaracterização por empresas imobiliárias interessadas na edificação de megacondomínios, repudiados pelos antigos

${ }^{9}$ Mais precisamente, às 23:30 horas. moradores, para quem esses empreendimentos

[...] às vezes acabam ocupando o quarteirão inteiro, sem diálogo com a rua, o bairro e o entorno. As pessoas que moram nesses condomínios não têm nenhuma relação com o bairro, nenhuma história de vida com o bairro... Simplesmente pegam o carro e vão para o trabalho, e quando querem se divertir se dirigem ao shopping. (entrevista com integrante do movimento da Vila Sônia).

Por isso mesmo, organizados em entidades e comunidades na internet, moradores de diversos bairros paulistanos têm se mobilizado em defesa de sua qualidade de vida e declarado uma verdadeira guerra contra os grandes lançamentos imobiliários, alcançando algumas vitórias. No Butantã, por exemplo, associações do bairro obtiveram uma liminar na justiça que paralisou a operação urbana Vila Sônia. Sem consultar a população, essa operação estimulava a construção de prédios e previa a atração de mais 37 mil pessoas para a área, permitindo que as construtoras elevassem empreendimentos residenciais e comerciais em troca de taxas antecipadas pagas à prefeitura.

Na Vila Mariana, cujo valor do metro quadrado foi dos que mais cresceu na cidade, grupos como o "Salvem os quintais" ou "Do outro lado do muro" se mobilizam para tentar frear a edificação de espigões em suas ruas arborizadas e ainda cheias de casinhas. Na Vila Romana, têm ocorrido protestos contra as construtoras e seu "espetáculo imobiliário", que vendem o bairro como "[...] repleto de cultura local, casinhas charmosas", enquanto tratores e escavadeiras o exterminam" (Folha de S.Paulo, 22 nov. 2011).

Em Pinheiros, moradores procuraram impedir a demolição de um casarão tradicional e de significativo valor arquitetônico, localizado em uma área de $2.000 \mathrm{~m}^{2}$, comprado por uma construtora para a edificação de prédios, propondo sua transformação em um centro cultural. Um grupo denominado "Moradores de Pinheiros contra a verticalização desenfreada" conseguiu obter uma liminar contra essa demolição, mas o casarão foi derrubado na calada da noite, e o grupo luta agora pela sua transformação em um parque público (Folha de S.Paulo, 30 abr. 2012). 


\section{O caso extremo de Salvador}

Em nenhuma dessas cidades, porém, o fenômeno em discussão chegou aos extremos registrados em Salvador, capital do Brasil na fase colonial, que hoje constitui a terceira maior cidade do país, com uma população de 2.675.656 habitantes.

Em Salvador, o poder da coalisão de interesses privados sobre o desenvolvimento da cidade cresceu bastante nos últimos anos, como analisam Carvalho e Pereira (2012), inclusive pela sua estreita e agora explícita articulação com a prefeitura local. Essa articulação se expressou na aprovação, em 2004, de um novo Plano Diretor de Desenvolvimento Urbano, gestado e orientado para os interesses do mercado imobiliário, flexibilizando e alterando normas e instituindo outros mecanismos para facilitar (ainda mais) a apropriação por esses setores de mais valia urbana. Pouco preocupado com os grandes problemas da cidade, como a carência de infraestrutura e serviços básicos, a habitação popular ou o transporte e a mobilidade, o Plano visou basicamente à modificação de parâmetros construtivos e a elevação do gabarito na "área nobre" da cidade, como desejavam os empreendedores imobiliários.

Bastante questionado, esse Plano foi aprovado pelos vereadores na calada da noite, recebeu muitas e suspeitas emendas e terminou sendo objeto de uma ação por parte do Ministério Público, entre outros motivos porque desrespeitava as disposições do Estatuto da Cidade no que tange à participação popular. Mas esse processo não teve efeitos práticos, pois o Ministério Público só ganhou a ação quatro anos depois, quando o referido Plano já tinha sido revisado, com o mesmo tipo de motivação. O eixo central dessa revisão foi um claro incremento nos parâmetros urbanísticos de aproveitamento do solo (Sampaio, 2010), aumentando a intensidade de ocupação por zonas, sem apresentar estudos técnicos que justificassem as mudanças, ou ao menos avaliassem os seus impactos em termos sociais, ambientais e logísticos.

Além disso, no início de 2010, a Prefeitura lançou um conjunto de projetos alinhavados frou- xamente pelo denominado planejamento estratégico, "doado" por empresas do setor imobiliário à cidade, que, com o pretensioso título de "Salvador Capital Mundial” (Prefeitura Municipal de Salvador, 2010), propunha um amplo conjunto de intervenções para direcionar o seu desenvolvimento, com singelas declarações do alcaide:

Recentemente apresentamos a empresários, à imprensa e à sociedade o masterplan intitulado Salvador Capital Mundial, um plano completo de reconfiguração urbana para Salvador, com 22 projetos estruturantes, incluindo novas avenidas, viadutos, requalificação da Orla Marítima, da Cidade Baixa e Península Itapagipana, elaborados por um grupo de arquitetos e urbanistas [...].

As diversas empresas participantes, dos setores de arquitetura, urbanismo, construção pesada e outras, contribuíram da forma que entenderam como mais eficaz para a elaboração deste trabalho. Um projeto que a Prefeitura de Salvador não teria como encomendar e pagar a famosos escritórios de planejamento urbano (João, 2010b. Conforme Carvalho e Pereira, 2011. Grifo dos autores).

Como ressaltam Carvalho e Pereira (2012), esses projetos não formavam um corpo coerente nem integravam um plano único, sendo a expressão de interesses pontuais e direcionados para áreas da cidade sobrevalorizadas e saturadas (caso das áreas onde o adensamento construtivo foi além da capacidade de suporte da infraestrutura instalada), ou para áreas do centro tradicional, com menor valorização do solo e onde, como forma de viabilizar seu uso, o projeto justificaria a desapropriação dos imóveis dos atuais proprietários. Como seria de esperar, a localização dessas intervenções ignorava as áreas socialmente carentes da cidade, concentrando-se naquelas onde a especulação imobiliária pode ampliar seus ganhos.

Nem o detalhamento das propostas nem a identificação dos seus financiadores foram divulgados, com os projetos circulando na forma de vistosas publicações elaboradas por agências de publicidade. Mas, apesar da tentativa de manipulação da opinião pública, essa “doação" teve uma repercussão bastante negativa, com pronunciamentos contrários de vereadores da oposição, da imprensa e de organizações da sociedade civil. Essa reação foi tão significativa, que uma fundação liga- 
da a empresas construtoras, que "doara” um dos projetos, veio a público desautorizando sua utilização pela prefeitura, considerando-se mal compreendida e injustiçada pelas críticas.

Nesse processo de flexibilização e desrespeito às normas de uso do solo e construção, destaca-se a instituição de um instrumento urbanístico como o TRANSCON, que cria a "transferência do direito de construir" sem o mapeamento das áreas cujos direitos de construir podem ser transferidos (“áreas doadoras”) para outras áreas (“áreas aptas a receber adensamento”), possibilitando a realização de qualquer operação independentemente de haver restrições urbanísticas, constituindo uma espécie de licença para transgredir qualquer norma restritiva ${ }^{10}$ (Sampaio, 2010). Os resultados, para a cidade, tendem a ser a maior saturação das áreas já saturadas e os problemas ocasionados pelo adensamento excessivo em termos ambientais, de infraestrutura, transportes, etc. Sampaio (2010, p.174) mostra que uma área infraestruturada e adensada como a Pituba recebeu 33,7 \% dos empreendimentos TRANSCON aprovados entre 1997 e 2009. Também é notável a elevação do número de empreendimentos que tem usado esse instrumento após 2004, ano de aprovação do novo PDDU, que foi revisto em 2008. Passou-se de uma média de 33,8 empreendimentos aprovados por ano, entre 1997 e 2004, para uma média de 56,2 por ano, a partir de 2005.

Significativamente, a estreita articulação entre o governo local e o capital imobiliário é explicitada pelo próprio órgão responsável pelo licenciamento de construção e atividades, a Superintendência de Controle e Ordenamento do Uso do Solo do Município (SUCOM).Em seu site, em 2009, constava que:

${ }^{10}$ Com base nesse instrumento, uma incorporadora obteve um alvará para a construção de um luxuoso edifício residencial de três torres com 19 andares em frente ao mar de Piatã, na Orla Marítima, onde o PDDU restringe a altura máxima dos prédios a 39 metros para evitar o sombreamento da praia e facilitar a ventilação nas quadras interiores. Esses edifícios têm 60 metros, sua área construída foi irregularmente ampliada e os padrões de recuo mínimo não foram obedecidos (A Tarde, 25/05/ 011, p.A9). Ações judiciais do Ministério Público da Bahia levaram à paralisação da obra e à proibição da autorização para uso do potencial construtivo em empreendimentos residenciais na orla atlântica, que viabilizam a construção de grandes edifícios nessa área (A Tarde, 29/09/2010).
Visando ao crescimento imobiliário da cidade de Salvador e estreitar o relacionamento com os empresários do ramo de construção, a SUCOM firmou na tarde desta quinta-feira (06) um convênio com a Associação de Dirigentes de Empresas do Mercado Imobiliário (ADEMI). A assinatura do documento aconteceu no auditório do Empresarial Niemeyer e teve como público os associados da ADEMI (SUCOM, 2009).

Esse convênio significou, segundo as próprias palavras do então superintendente, “[...] trabalhar junto com a ADEMI [...] uma parceria como essa nasce em consonância com o novo modelo de gestão que o prefeito João Henrique vem trazendo para a cidade desde 2005”. Além disso, em maio de 2011, por ocasião do aniversário da cidade, o prefeito declarava que,

[...] para transformar Salvador em uma capital mundial (sic), é preciso projetos arrojados, modernos, que integrem o meio ambiente e as edificações à paisagem urbana, garantindo a mobilidade e mais qualidade de vida para a sua população.

O projeto batizado de Salvador Capital Mundial prevê soluções para o transporte, trânsito e crescimento da cidade. Serão abertas novas vias de tráfego, implantados sistemas modernos de transporte, revitalização da orla, requalificação e ampliação da estrutura turística.

A participação do mercado imobiliário neste processo de alavancagem do crescimento econômico de Salvador tem sido fundamental para consolidar o novo momento em que vivemos. Nos últimos anos a cidade teve alterada sua dinâmica com o ingresso de empreendimentos arrojados e de ponta, liderados por construtoras de grande porte oriundas de outros estados. A capital fervilha na área da construção. São empreendimentos residenciais e comerciais que vão tomando forma e ampliando a oferta de mão de obra em um segmento que não para de crescer (A Tarde, mar. 2011).

Com esse discurso sobre a cidade mundial, a competitividade urbana e o crescimento econômico, ele procurava obscurecer os efeitos devastadores desse novo padrão de governança sobre a cidade, onde se incluem a degradação do meio ambiente, com a destruição de diversas áreas verdes e dos últimos resquícios da mata atlântica, ${ }^{11} \mathrm{O}$

1 Segundo estudos de Santos (2009), a área no entorno da Av. Paralela, onde hoje se localiza a expansão imobiliária mais vigorosa, havia perdido 247 hectares de floresta densa entre 1989 e 2002. 
aterramento de nascentes e lagoas, a criação de obstáculos à circulação dos ventos, a elevação da temperatura, a perda da mobilidade urbana e o aumento dos congestionamentos, a degradação dos espaços públicos e do patrimônio histórico-cultural da cidade, o crescimento da segregação, da fragmentação, das desigualdades sociais e urbanas.

Em junho do mesmo ano, alegando que, para receber novos hotéis e sediar algumas partidas do campeonato mundial de futebol em 2014, ainda "era preciso mudar as regras", o prefeito aprovou na Câmara uma nova Lei de Ocupação, Ordenamento e Uso do Solo, alterando dispositivos do Plano Diretor de Desenvolvimento Urbano. Entre outros aspectos, essa lei reduziu a representatividade e alterou os poderes do Conselho da Cidade e do Conselho Municipal do Meio Ambiente, extinguiu o Parque Ecológico do Vale Encantado, ultima reserva da Mata Atlântica do município, localizado em um cobiçado espaço na área nobre da cidade, e ampliou bastante o gabarito da Orla Atlântica, permitindo a construção de grandes edifícios e hotéis nesse valorizado espaço urbano, mesmo à custa do sombreamento das praias e de uma redução da aeração da cidade.

Além disso, no primeiro semestre de 2012, o executivo municipal elaborou um polêmico projeto de revitalização do centro antigo, denominado como Santa Tereza, denominado "Humanização do Bairro", ignorando os diversos pedidos de audiência e diálogo com os moradores tradicionais e de baixo poder aquisitivo daquela área, que tenderiam a ser expulsos para dar lugar a empreendimentos de luxo destinados ao turismo. Apresentado no $20^{\circ}$ Congresso Centro Ibero-americano de Desenvolvimento Estratégico Urbano (CIDEU), não por acaso esse projeto tinha uma poligonal similar à traçada por projetos gestados por empreendedores privados e suscitava diversas outras questões, levando a uma reação e mobilização dos moradores e de movimentos da sociedade organizada e à abertura de um inquérito civil na $6^{\text {a }}$ Promotoria de Habitação do Ministério Público da Bahia. (A Tarde, 29 jul. 2012).

Frente a essas reações, o prefeito e seus assessores passaram a bradar contra o que denomina- vam como "forças do antagonismo" e "do atraso" (incluindo, entre elas, o Ministério Público, os órgãos de fiscalização e defesa do meio ambiente e do patrimônio histórico, a imprensa e os movimentos sociais), que estariam gerando "uma insegurança jurídica", impedindo a construção de "parcerias saudáveis com a iniciativa privada", a geração de empregos e o próprio desenvolvimento da cidade.

Finalmente, quando restavam apenas dois meses para o fim do seu mandato, mais uma vez sem maior publicidade ou qualquer discussão, ele enviou à Câmara um conjunto de projetos que legalizavam e institucionalizavam as transformações urbanísticas perseguidas ao longo do referido mandato. Tais projetos recuperavam as disposições do PDDU e da LOUS (que se encontravam sub judice no Tribunal de Justiça da Bahia, em decorrência de Ação Direta de inconstitucionalidade proposta pelo Ministério Público); definiam as condições para aplicação da outorga onerosa e do uso de transferência onerosa do direito de construir de forma adversa às finanças municipais; ampliavam o gabarito das edificações na Orla e em quadras próximas e o coeficiente de aproveitamento de diversas áreas; regularizavam construções embargadas por não atenderem às normas vigentes; atingiam negativamente o patrimônio ambiental e cultural da cidade. Eram feitas tamanhas concessões a interesses privados, que um dos participantes da equipe de transição do novo prefeito eleito chegou a afirmar que, se aprovados, "esses projetos permitiriam um verdadeiro saque na prefeitura” (A Tarde, 12 nov; 18 nov. 2012).

Ainda assim, esses projetos foram aprovados pela grande maioria de uma Câmara também em fim de mandato e com um alto nível de renovação. Essa aprovação ocorreu na madrugada de uma sessão, na qual foram agregadas novas e suspeitas emendas, que não chegaram a ser lidas e, muito menos, foram objeto de discussão. Solicitada por uma das vereadoras, essa leitura foi negada pelo presidente da sessão.

Com essas características, como ressaltam Carvalho e Pereira (2012), no caso de Salvador, consolidou-se um processo que pode ser conside- 
rado como uma terceirização do planejamento e da gestão da cidade, com a transferência de atribuições de controle do uso e da ocupação do solo e da formulação de política, planos e projetos de desenvolvimento urbano da esfera pública para a esfera privada. Todos os seus grandes projetos têm em comum a falta de transparência, de discussão, de participação pública, com o repasse das atribuições tradicionais do Estado para uma coalizão de interesses econômicos. Contrariando ou deixando em plano absolutamente secundário os interesses e necessidades da grande maioria da população, esse processo transforma a cidade em um negócio, na acepção mais crua do termo, em que poucos ganham e quase todos perdem.

Alguns projetos foram apresentados de forma mais direta e imediata, a exemplo projeto Santa Tereza, situação em que os residentes na área do bairro Dois de Julho tenderiam a ser expulsos com a gentrificação pretendida. Ou os moradores do bairro de Itapagipe, que receberam com surpresa a notícia de um decreto de desapropriação de suas antigas moradias para a "revitalização" da área, que passou a despertar a cobiça do capital imobiliário pela sua localização nas bordas da Baía de Todos os Santos, com indenizações calculadas não pelos preços de mercado de seus imóveis, e sim pelos defasados valores do IPTU. ${ }^{12}$

Como seria de se esperar, a percepção dos referidos impactos e a deterioração das condições da cidade passaram a suscitar protestos e manifestações, levando o prefeito a experimentar uma enorme rejeição, e entidades da sociedade civil a tomarem diversas iniciativas para ampliar e qualificar o debate sobre o planejamento e a gestão municipal. Embora os frutos dessas iniciativas ainda não sejam perceptíveis e algumas condições se mostrem desfavoráveis, ${ }^{13}$ essas entidades permanecem aten-

${ }^{12}$ Um dos projetos do conjunto "Salvador Capital Mundial”, lançado em 2010, era justamente uma intervenção na área de Itapagipe, tendo sido o projeto elaborado por uma fundação privada, controlada por uma grande empreiteira, que, a partir da reação da imprensa e de setores organizados da sociedade, desautorizou sua utilização pela Prefeitura, conforme antes mencionado.

${ }^{13}$ Acossada pela precariedade habitacional, pelo desemprego e pela pobreza, boa parte da população soteropolitana transformou-se em presa fácil para o populismo e o clientelismo político, e isso vem se refle- tas e mobilizadas no sentido de reverter os retrocessos dos últimos anos.

\section{ALGUMAS CONSIDERAÇÕES FINAIS}

As evidências e análises apresentadas ao longo deste trabalho deixam patente como, entre as mudanças mais recentes e relevantes das cidades brasileiras, se inclui o abandono de boa parte das funções tradicionais de gestão e planejamento de responsabilidade do Estado e uma afirmação crescente da lógica da coalizão de interesses privados nos processos do seu desenvolvimento. Para isso tem contribuído a influência do ideário neoliberal e a difusão do chamado "empreendedorismo urbano”, que enfatiza, como questão central, a busca de uma competitividade para atrair os capitais que circulam no espaço sem fronteiras do mundo globalizado, conformando um novo padrão de governança e propiciando um novo poder e protagonismo à mencionada coalizão.

Como assinalam Carvalho e Pereira (2012), embora a mercantilização do desenvolvimento urbano não constitua uma novidade na trajetória do Brasil e de outros países, o que se configura agora é um padrão de governança no qual as opções e decisões vêm deixando de fazer parte das atribuições do poder público. Ele passa a operar como um ator coadjuvante, referendando decisões privadas, priorizando grandes obras e ajustando o arcabouço jurídico urbanístico às demandas do capital, a pretexto de que isso é indispensável para atrair investimentos e ampliar o volume de emprego.

Nesse contexto, a avaliação das prioridades e impactos urbanísticos, sociais e ambientais da implementação de grandes empreendimentos e equipamentos e das transformações urbanas deixa de ser um critério válido, mesmo quando esses impactos venham a se traduzir na falência do sistema de transportes, na degradação ambiental, na destruição do patrimônio cultural e arquitetônico,

tindo sobre o perfil dos prefeitos, a composição e atuação da Câmara de Vereadores e a própria capacidade de organização e mobilização social. 
na dispersão incontrolada do tecido urbano, no adensamento de áreas saturadas e no aumento da exclusão e da segregação sócio-residencial.

É verdade que o tempo se encarregou de desfazer as ilusões do planejamento normativo e racionalista quanto à sua capacidade de modelar as cidades, ignorando ou minimizando determinantes estruturais, a lógica e os conflitos mais amplos da dinâmica urbana no capitalismo. Mas isso não significa que o caminho para o alcance daqueles objetivos seja tentar repetir (agora como farsa) experiências como a de Barcelona, replicando formas e artefatos difundidos e generalizados globalmente, multiplicando os "não lugares", mercantilizando e espetacularizando a cidade e entregando seus destinos ao capital, sem levar em conta sua qualidade de vida, sustentabilidade e coesão social.

Por isso mesmo, têm se multiplicado os conflitos entre os que vivem na cidade, interessados, sobretudo, na sua qualidade de vida, e a coalizão de interesses econômicos, que a consideram como uma máquina de crescimento e de produção de lucros, levando à mobilização de grupos mais ou menos amplos de moradores e suscitando protestos e contestações.

Com o respaldo das disposições constitucionais do Estatuto da Cidade e a intervenção do Ministério Público, algumas delas têm crescido e obtido sucesso, conseguindo barrar ou reverter certas mudanças, como exemplifica a trajetória de Natal. Mas como, no Brasil, o conflito entre a coalizão de interesses imobiliários e os usuários da cidade não atinge a todos da mesma forma e as disputas se dão principalmente em torno dos recursos públicos entre os moradores da cidade formal e da cidade informal, muitas das reações não alcançam uma maior amplitude, ficando restritas a movimentos pontuais e defensivos em bairros residenciais das classes médias, sem maiores impactos sobre os rumos da cidade. Explicitando a dimensão política dos fenômenos analisados, isso também deixa patente como, na luta pela qualidade de vida e por uma gestão democrática e justa da cidade, essas mobilizações precisam pensá-la como um todo, assumindo um caráter mais amplo, soli- dário e unificado, capaz de envolver os diversos segmentos da população.

Recebido para publicação em03 de março de 2013 Aceito em 15 de agosto de 2013

\section{REFERÊNCIAS}

BAYON, Maria Cristina. Desigualdad y procesos de exclusion social. Concentracion socioespacial de desvantajas en el gran Buenos Aires y la Ciudad de México. Estúdios Demográficos y Urbanos. Mexico, El Colégio de México, v. 23, n.1, p.123-150, enero-abril, 2008.

BORJA, Jordi; CASTELS, Manuel. Local e global. La gestión de las ciudades en la era de la información. Madrid: Taurus, 1997.

CARDOSO, Adauto Lúcio; ARAGÃO, Themis Amorim. Reestruturação do setor imobiliário e o papel do Programa Minha Casa Minha Vida. In: SEMINÁRIO DA RED IBEROAMERICANA DE INVESTIGADORES SOBRE GLOBALIZACIÓN Y TERRITORIO, 12, Belo Horizonte, 2012. 23 p.

CARVALHO, Inaiá M. M. de; PEREIRA, Gilberto Corso. A cidade como negócio. Salvador: EDUFBA, 2012. 23 p. vador: EDUFBA,
(Org.) Como anda Salvador. 2.ed. SalDinamica de una metrópoli periferica en Brasil. Estudios Demograficos y Urbanos. Mexico, El Colegio de Mexico, v.25, n.2, p.395-427, 2010.

COBOS, Emilio Pradilla. Formas productivas, fraciones de capitaly reconstrucion urbana em America Latina. In: SEMINÁRIO DA REDE IBEROAMERICANA DE PESQUISADORES SOBRE GLOBALIZAÇÃO E TERRITÓRIO, 12, Belo Horizonte, 2012.

CLEMENTINO, Maria do Livramento M. Rio Grande do Norte: novas dinâmicas, mesmas cidades. In: GONÇALVES, Flora; BRANDÃO, Carlos A.; GALVÃ̃, Antonio C. (Org.) Regiões e cidades. Cidades nas regiões. São Paulo: UNESP, 2003. p. 387-404.

CORDERA, Rolando; KURI, Patrício R.; ZICARDI, Alícia (Coord.). Pobreza, desigualdad y exclusion social en la ciudad del siglo XXI. Mexico: Siglo XXI: UNAM, 2008. $438 \mathrm{p}$.

DUARTE, Marise C. de Souza. Espaços especiais urbanos. Desafios à efetivação dos direitos ao meio ambiente e à moradia. Rio de Janeiro: Observatório das Metrópoles, 2011. 528 p.

DUHAU, Emílio. As novas formas de divisão social do espaço nas metrópoles latino americanas: uma visão a partir da cidade do México. Caderno CRH: revista do Centro de Recursos Humanos da UFBA, Salvador, v.18, n. 45, set./dez., 2005.

FERNANDES, Ana. Salvador, uma cidade perplexa. Carta Maior, Salvador, 08 dez 2012.

FERREIRA, João Sette. Wbitaker. O mito da cidade global. O papel da ideologia na produção do espaço urbano. Petrópolis: Vozes; São Paulo: UNESP; Salvador: ANPUR, 2007. 248 p.

FIX, Mariana. São Paulo, cidade global: fundamentos financeiros de uma miragem. São Paulo: Boitempo, 2007. $191 \mathrm{p}$. 
2001. 207 p.

Parceiros da exclusão. São Paulo. Boitempo,

GONZALEZ, Luis Maurício Cuervo, América Latina: metropoles en mutación? In: SEMINÁRIO INTERNACIONAL DE LA RED DE INVESTIGADORES EN GLOBALIZACIÓN Y TERRITORIO,11, Mendoza, 2010.

HARVEY, David. Do admistrativismo ao empreendedorismo: a transformação da governança urbana no capitalismo tardio. In: A produç̃a $\mathrm{Ca}$ pitalista do espaço. São Paulo: Anablume, 2005. 252 p.

JANOSCHKA, Michael. El nuevo modelo de la ciudad latinoamericana: fragmentacion y privatizacion. EURE, Santiago do Chile, v.28, n.85, 2002.

LOGAN, John R., MOLOTCH, Harvey L. Urban fortunes. California: University California Press, 1987.

MARCUSE, Peter; KEMPEN, Ronald. Globalizing cities: new spatial order? London: Backwell, 2000.

MARICATO, Ermínia. As idéias fora do lugar e o lugar fora das idéias. Planejamento urbano no Brasil. In: ARANTES, Otília; VAINER, Carlos; MARICATO, Ermínia. A cidade do pensamento único. 3.ed. Petrópolis: Vozes, 2002.

O impasse da política urbana no Brasil. Petrópolis: Vozes, 2011. 219 p.

MATTOS, Carlos A. Santiago do Chile, globalizacion y expansion metropolitana: lo que existia sigue existiendo EURE, Santiago do Chile, v.25, n.76, 1999.

Redes, nodos e cidades: transformação da metrópole latino americana. In: RIBEIRO, Luiz César Q. (Org. Metrópole: entre a coesão e a fragmentação, a cooperação e o conflito. São Paulo: Perseu Abramo; Rio de Janeiro: FASE/Observatório das Metrópoles, 2004.

Globalización y metamorfosis metropolitana en América Latina: de la ciudad e lo urbano generalizado. Documentos de Trabajo CEDEUR. Madrid, n.8, 2010a.

Globalización y metamorfosis metropolitana en América Latina. Quito: OLACCHI; Município del Distrito Metropolitano de Quito, 2010b. 374 p.

MOURAD, Laila N. Notas sobre o Projeto Nova Luz. Salvador: $2012.14 \mathrm{p}$.

NOBRE, Eduardo A. G. Quem ganha e quem perde com os grandes projetos, urbanos? Avaliação da Operação Ur - nos IPPUR, Rioda Agua Espraiada em São Paulo. Cader-

PRÉTECEILLE, Edmond. A evolução da seoregação social e das desigualdades urbanas: o caso da metrópole parisiense nas últimas décadas. Caderno CRH: revista do Centro de i Recursos Humanos, Salvador, n. 36, p.27-48, 2003.

RIBEIRO, Luiz César Q. (Org.). Metrópole: entre a coesão e a fragmentação, a cooperacão e o conflito. São Paulo: $\dot{2}$ Perseu Abramo; Rio de Janeiro: FASE/Observatório das Metrópoles, 2004.

SABATINI, Francisco; CÁCERES, Gonzalo; CERDA, Jorge. Segregação residencial nas principais cidades chilenas: tendências das três últimas décadas e possíveis cursos de ação. Espaço \& Debates: revista de Estudos Regionais e Urbanos. São Paulo, v. 24, n. 45, jan./jun., p. 64-74, 2004. SAMPAIO, A. Heliodório. 10 necessárias falas: cidade, arquitetura e urbanismo. Salvador: EDUFBA, 2010.

SANTOS. C. E. da S. A expansão urbana sobre os remanescentes florestais situados no entorno da Avenida Luiz Viana Filho, Salvador - Bahia. 2009. Dissertação (Mestrado de Engenharia Ambiental Urbana) - UFBA. Salvador, 2009.

SASSEN, Saskia. The global city: New York, London,
Tokyo. New Jersey: Princeton University Press, 1991.

SHAPIRA, Marie France Prevot. Segregação, fragmentacão, sucessão: a nova geografia social de Buenos Aires. Novos Estudos CEBRAP, São Paulo, n.56, mar., p.169183, 2000.

TASCHNER, Suzana P.; BÓGUS, Lúcia M. M. São Paulo como Patchwork: fragmentos de uma cidade segregada. Cadernos Metrópoles. São Paulo, n.1, 1999

VAINER, Carlos. Pátria, empresa e mercadoria. Notas sobre a estratégia discursiva do planejamento urbano. In: ARANTES, Otília; VAINER, Carlos; MARICATO, Ermínia. A cidade do pensamento único. 3.ed. Petrópolis: Vozes, 2002 .

VEIGA, Danilo. Estratificación social y desigualdades territoriales en la globalización: estudios de caso. In: SEMINÁRIO INTERNACIONAL DE LA RED IBEROAMERICANA DE INVESTIGADORES SOBRE GLOBALIZACIÓN Y TERRITORIO, 11, Mendoza, 2010.

VELTZ, Pierre. Mondialisation, villes et territoires. L'economie d'archipel. Paris: Press Universitaires de France, 1996.

VILLAÇA, Flávio. As ilusões do Plano Diretor. São Paulo, 2005. Disponível em: www.flaviovillaça.arq.br. Acesso em: ago. 2011

\section{REFERÊNCIAS DOCUMENTAIS}

A TARDE. Nome do Projeto remete a crime que assustou Salvador. 29 jul. 2012. C1.

A TARDE. João critica órgãos de fiscalização e Caetano. Salvador, 24 jul 2012. p. B1.

A TARDE. 28/06/2012

A TARDE. Caderno Muito, Salvador, 29 fev 2011

A TARDE. Alvará de prédio não segue gabarito, diz PM. Salvador, 22 maio 2010. p. A4.

A TARDE. Suspensas licenças de prédios altos na orla. Salvador, 22 set. 2010 . p. A5.

A TARDE. Um mês depois, prefeitura omite quem patrocina projetos da "Capital Mundial". Salvador 28 fev. 2010 p. B2.

EXAME. A maior alta do mundo. São Paulo, Ed. Abril: Ed. 992, v.45, n.9. 2011. p. 34-50.

FOLHA DE SÃO PAULO. O projeto Nova Luz deve ser repensado? São Paulo, 16 fev. 2013. p. A3.

FOLHA DE SÃO PAULO. Praga de sete anos. São Paulo, 26 jan. 2013. p. A2.

FOLHA DE SÃO PAULO. Prefeitura “engaveta” o projeto Nova Luz. São Paulo, 24 jan. 2013. p. C5.

FOLHA DE SÃo PAULO. Desapropriação na Nova Luz cabe à Prefeitura, diz Haddad. São Paulo, 16 dez. 2012. p. C1.

FOLHA DE SÃO PAULO. Imobiliária Prefeitura S. A. São Paulo, 08 jul 2011. p. A3.

FOLHA DE SÃO PAULO. Juiz barra venda de área no Itaim.São Paulo, 05 ago. 2011. p.CI.

FOLHA DE SÃO PAULO. Novos empreendimentos imobiliários têm tendência a se fechar para a cidade. São Paulo, 22 nov. 2011. p. C3.

FOLHA DE SÃO PAULO. Moradores se unem e barram crescimento de bairro paulistano. São Paulo, 22 nov. 2011. p. C1. 
FOLHA DE SÃO PAULO. Casarão vira ícone de ação contra a verticalização. São Paulo, 24 maio 2012.

Http//movimentodesocupa.wordpress.com/ . Acesso em: 24 abr. 2012.

JOÃO Henrique acusa barraqueiros de intransigência e advogado rebate. Disponível em: http:// w w w a t a rdeonline.com.br/cid a d e s / noticia.jsf?id=5611798. Acesso em: 20 maio 2011, 2010a

JOÃO Henrique defende Capital Mundial. Disponível em: http://www.teiadenoticias. com.br/noticia/cidade/jo-ohenrique-defende-capital-mundial. Acesso em: 20 maio 2011, 2010b.

JORNAL METRÓPOLES, Salvador, 17 jun. 2011.

MOVIMENTO VOZES DA CIDADE. Denúncia. Salvador, jan. 2012.
OCEPLAN, Orgão Central de Planejamento/PMS. EPUCS: uma experiencia de planejamento urbano. 1976.

PREFEITURA MUNICIPAL DE SALVADOR - PMS. Álbum EPUCS. Salvador: OCEPLAN/PLANDURB, 1976.

PREFEITURA MUNICIPAL DE SALVADOR - PMS. Salvador capital mundial: a cidade do nosso futuro. Salvador: PMS, 2010.

SUCOM firma convênio em prol do crescimento imobiliário da cidade. Disponível em: http:// www.sucom.ba.gov.br/noticias/sucom-firma-convênioem-prol-do-crescimento-imobiliário-da-cidade.aspx. Acesso em: 16 maio 2011. 2009.

THE Economist. A special report in property. London, v.398, n.8723. 2011. 


\section{REAL ESTATE CAPITAL AND URBAN DEVELOPMENT}

\section{Inaiá Maria Moreira de Carvalho}

This article analyzes how the diffusion of a pattern of governance centered on a search for a "competitive urbanism" has led the State to abandon some of its traditional management and urban planning functions, transferring these instead, to private actors, which constitutes a growing affirmation of the logic of real estate capital over the structure of cities and the life of their populations. Discussing the recent evolution of three Brazilian capitals, Natal, São Paulo and Salvador, it analyzes the discourses and procedures that are used to justify and legitimate this new pattern of governance, and equally underlines its adverse effects in social, environmental and urban terms.

KeY-WoRDs: Metropolis. Real estate capital. Urban development.

\section{CAPITAL IMMOBILIER ET DÉVELOPPEMENT URBAIN}

\section{Inaiá Maria Moreira de Carvalho}

Cet article analyse la façon dont la diffusion du modèle de gouvernance centré sur la recherche d'une "compétitivité urbaine" a mené l'Etat à abandonner une partie de ses fonctions traditionnelles de gestion et de planification urbaine et à les transférer à des acteurs privés. Ceci permet à la logique du capital immobilier de s'affirmer de plus en plus quant à la structure des villes et à la vie de leurs populations. A partir de débats concernant l'évolution récente de trois capitales brésiliennes, Natal, Sao Paulo et Salvador, cet article analyse les discours et les procédés utilisés pour justifier et légitimer ce nouveau modèle de gouvernance, tout en soulignant ses effets néfastes en termes sociaux, environnementaux et urbains.

Mots-CLÉs: Métropoles. Capital immobilier. Développement urbain.

Inaiá Maria Moreira de Carvalho - Doutora em Sociologia, Professora do Programa de Pós-Graduação em Ciências Sociais da Universidade Federal da Bahia (UFBA) e do Mestrado em Políticas Sociais e Cidadania da Universidade Católica do Salvador, Brasil. Pesquisadora do Centro de Estudos e Pesquisas em Humanidades - CRH - da Universidade Federal da Bahia, do CNPq e do Observatório das Metrópoles - Brasil. Tem experiência na área de Sociologia, com ênfase em Sociologia do Desenvolvimento e Sociologia Urbana, atuando principalmente nos seguintes temas: mercado de trabalho, transformações urbanas, pobreza e políticas sociais. Publicações recentes: Algumas Considerações sobre o Trabalho Precoce no Brasil. Revista de Politicas Publicas (UFMA), v. 16, p. 463-472-472, 2012; Mercado de Trabalho e Vulnerabilidade em Regiões Metropolitanas Brasileiras. Caderno CRH (UFBA. Impresso), v. 24, p. 397-412, 2011; Dinamica de una metrpoli periferica en Brasil. Estudios Demográficos y Urbanos de El Colegio de México, v. 25, p. 395-427, 2010 